\title{
Evaluating performance indices of a shopping centre and implementing HVAC control principles to minimize energy usage
}

\author{
Caglar Selcuk Canbay a, ${ }^{\mathrm{a}}$, Arif Hepbasli ${ }^{\mathrm{b}, 2}$, Gulden Gokcen ${ }^{\mathrm{c}, *}$ \\ a Energy Engineering Program, Izmir Institute of Technology, Gulbahce Koyu, Urla, 35437 Izmir, Turkey \\ ${ }^{\mathrm{b}}$ Faculty of Engineering, Mechanical Engineering Department, Ege University, Bornova, 35100 Izmir, Turkey \\ c Faculty of Engineering, Mechanical Engineering Department, Izmir Institute of Technology, Gulbahce Koyu, Urla, 35437 Izmir, Turkey
}

Received 24 November 2003; received in revised form 7 January 2004; accepted 12 January 2004

\begin{abstract}
Heating, ventilating and air-conditioning (HVAC) systems in buildings must be integrated with an efficient control scheme to maintain comfort under any load conditions. Efficient HVAC control is often the most cost-effective option to improve the energy efficiency of a building. However, HVAC processes are non-linear, and characteristics change on a seasonal basis so the effect of changing the control strategy is usually difficult to predict. The present study aims to reduce energy consumption by defining new HVAC control strategies and tuning control loops in a shopping centre. First, an energy audit was performed to investigate the potential for energy savings and to redefine the control scenarios, while a methodology for the shopping centre was developed. Performance indices were then calculated and compared with the yardsticks. Next, normalised performance indices were computed to reach out a better understanding of the building's efficiency. Finally, new strategies were implemented with the help of the existing building management system (BMS) and about 22\% of energy saving was achieved.
\end{abstract}

(C) 2004 Elsevier B.V. All rights reserved.

Keywords: Performance indices; Energy audit; HVAC control strategies; Building management system; Turkey

\section{Introduction}

Modern buildings and their heating, ventilating and air-conditioning (HVAC) systems are required to be more energy efficient, while considering to an ever-increasing demand for better indoor air quality, performance and environmental issues. The goal of HVAC design in buildings is to provide comfort to the occupants for varying heating and cooling loads with the time of the day and of the year. HVAC system must be complemented with an efficient control scheme to maintain comfort under any load conditions. Efficient control will also reduce energy use by keeping the process variables (temperature, pressure, etc.) to their set points.

Buildings are further one of the biggest consumers of energy. In developed countries, buildings account for between

\footnotetext{
* Corresponding author. Tel.: +90-232-4986598;

fax: $+90-232-4986505$.

E-mail addresses: canbayc@ hotmail.com (C.S. Canbay),

hepbasli@bornova.ege.edu.tr (A. Hepbasli), guldengokcen@iyte.edu.tr

(G. Gokcen).

${ }^{1}$ Tel.: +90-232-4986598; fax: +90-232-7506505.

2 Tel.: +90-232-7506598; fax: +90-232-7506505.
}

30 and $40 \%$ of the total energy consumed. Another alarming fact is that their energy consumption seems to be on the rise [1].

The share of energy used in the Turkish buildings is $36 \%$, with an average value of the years from 1980 to 2000 [2]. In 2001, of Turkey's end use energy, $34.48 \%$ was used by the residential-commercial sector. The share of this sector in this breakdown is expected to continue to decrease at approximately $9-12 \%$ per year and to reach 28 and $26 \%$ in 2005 and 2010, respectively. In a study performed by Utlu and Hepbasli [3], the energy-efficiency values for the Turkish residential-commercial sector in 2001 were found to be $55.75 \%$, while the exergy-efficiency values obtained were $8.98 \%$ in the same year. This study clearly indicated the necessity of the planned studies towards increasing exergy efficiencies in the sector studied and especially the critical role of policy-makers in establishing effective energy-efficiency delivery mechanisms throughout the country.

In general, most of the energy is used to maintain acceptable comfort levels within buildings. Of this, lighting and HVAC systems form the largest consumption items. Studies indicate that air-conditioning is responsible for between 10 and $60 \%$ of the total building energy consumption, de- 
pending on the building type [4-6]. This clearly indicates that the HVAC system of a building has a large potential for energy saving. A cost-effective way to improve the energy efficiency of a HVAC system, without compromising indoor comfort, is the implementation of an efficient control.

The aim of this study is to reduce energy consumption by defining new HVAC control strategies and tuning control loops in a shopping centre, which equipped with building management system (BMS). An energy audit was first conducted according to "Energy Audit Workbook of Washington State University Energy Program" [7] to determine the end-user breakdown of the energy consumption. The outcome of this audit was then used to identify the largest energy consumers, which are usually also the areas with the largest energy saving potential. Next, the performance of the building was evaluated and compared with the yardsticks, while normalised performance indices were calculated to better measure the efficiency of the building. Finally, an action plan was identified to implement the HVAC control strategies for reducing energy consumption and the results obtained were compared with the proceeding values.

\section{Building information and characteristics studied}

\subsection{General}

The shopping centre is located at Inciralt, Izmir, Turkey. The building consists of five air-conditioned zones with a floor area of about $16,000 \mathrm{~m}^{2}$; hypermarket, cafe and restaurant and star park (children playground) are on the ground floor (Fig. 1), while non-food store and offices are on the first floor (Fig. 2). The building has south-east and south-west facing windows, with conventional glazing.

All office windows face towards south-west and have adjustable external venetian blind for shading. Each office is air-conditioned by its own fan coil unit (FCU). Lighting is done by fluorescent bulbs in the offices as well as in the hypermarket. Most of the offices are equipped with computers.

The shopping centre houses an average of 11,000 people per day on the weekdays and 20,000 people per day on the weekends. Working hours and occupancy schedule of the zones are given in Table 1. Building occupancy profile should give an idea to refresh the HVAC control strategies due to daily, weekly and annual profiles of the occupancy. Figs. 3-5 illustrates daily, weekly and monthly building occupancy profile consequently.

\subsection{HVAC system definition}

The HVAC system is a constant volume, variable air temperature system. It consists of a central cooling and heating plant and nine air handling units (AHUs) with flow rates from 10,000 to $54,000 \mathrm{~m}^{3} / \mathrm{h}$. There are two AHUs for hypermarket, two for non-food store, one for restaurant, one for cafe, one for offices, one for star park and one for the main entrance. In addition to AHUs, there are 14 separate exhaust fans. Fig. 6 shows simplified heating and cooling distribution lines.

The air is conditioned by cooling and heating coils, which are located inside the AHUs. Air is supplied to the conditioned space via ducting. It is returned from the space via

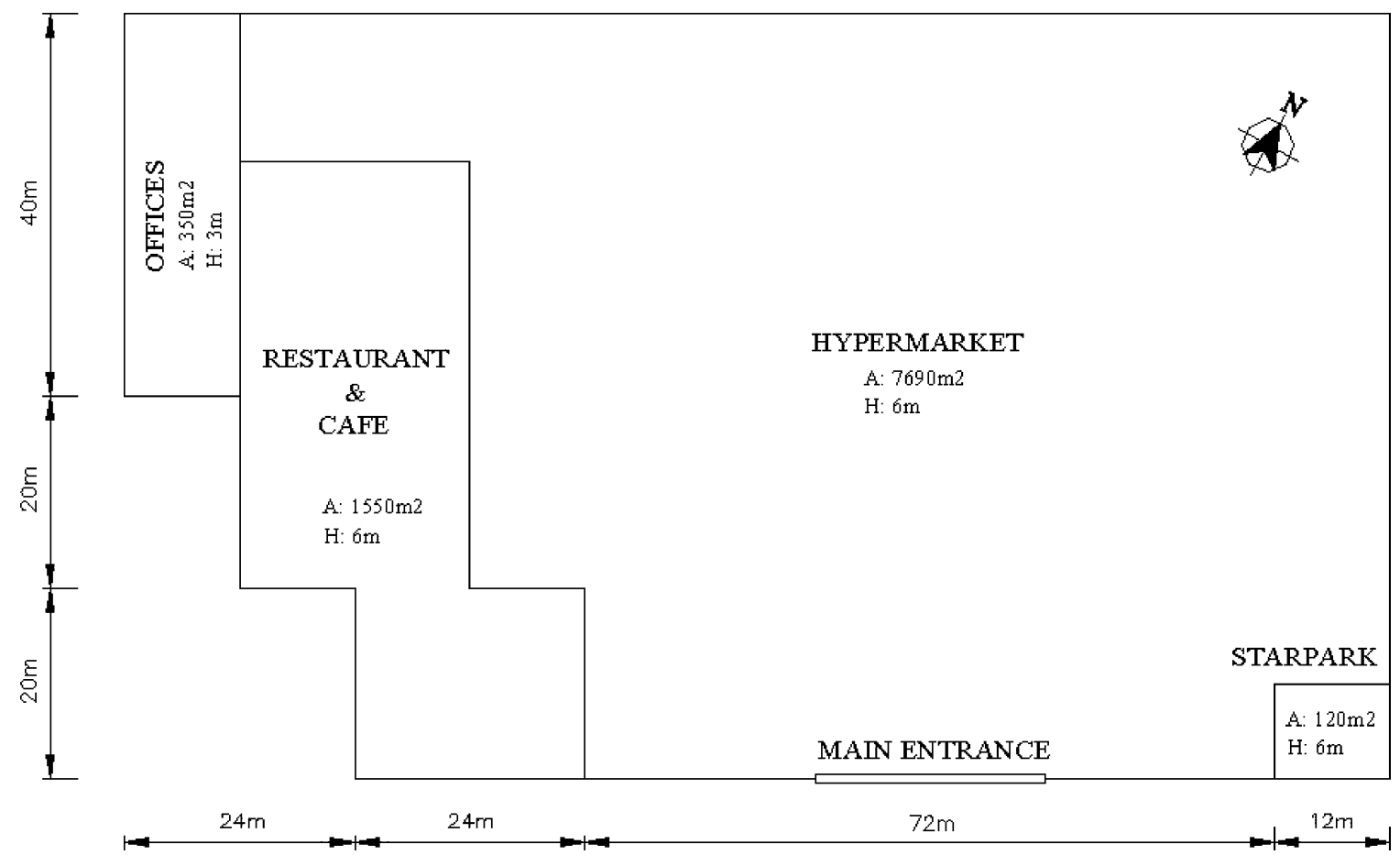

Fig. 1. A view of ground floor plan. 
Table 1

Building occupancy schedule

\begin{tabular}{|c|c|c|c|c|c|c|c|}
\hline \multirow[t]{3}{*}{ Zone } & \multirow[t]{3}{*}{ Area $\left(\mathrm{m}^{2}\right)$} & \multicolumn{3}{|c|}{ Weekdays } & \multicolumn{3}{|c|}{ Weekends and holidays } \\
\hline & & \multicolumn{2}{|c|}{ Working hours (h) } & \multirow[t]{2}{*}{ Number of people } & \multicolumn{2}{|c|}{ Working hours (h) } & \multirow[t]{2}{*}{ Number of people } \\
\hline & & From & To & & From & To & \\
\hline Hypermarket & 7690 & $10: 00$ & $24: 00$ & 5000 & $10: 00$ & $24: 00$ & 9000 \\
\hline Non-food store & 9360 & $10: 00$ & 24:00 & 3500 & $10: 00$ & $24: 00$ & 7500 \\
\hline Cafe and restaurant & 1550 & $10: 00$ & $24: 00$ & 2000 & 10:00 & $24: 00$ & 3500 \\
\hline Offices & 1830 & 08:00 & 08:00 & 270 & 08:00 & 08:00 & 320 \\
\hline Star park & 120 & $10: 00$ & 24:00 & 800 & $10: 00$ & 24:00 & 1400 \\
\hline
\end{tabular}

grills and ducts back to the roof where it mixes with outdoor air before returning to the AHUs. All AHUs are located at the roof. Fresh air is supplied to the building via grills located on the AHUs. Dampers are responsible for the outside air (OA)/return air (RA) mixing ratio. Cafe and restaurant and office AHUs work with a $100 \%$ fresh air.

The cooling of the air is done by cooling coils located inside each AHU. Digital proportional-proportional-integral (PPI) cascade controllers control the water flow through the coils to maintain a set temperature at sensors located in the RA ducts. Three parallel, reciprocating air-cooled chillers supply chilled water to all the cooling coils in the AHUs. Loading and unloading of the chiller compressors maintain a set return water temperature. Each has two compressors with a rating of $37 \mathrm{~kW}$ per compressor and a cooling capacity of $340 \mathrm{~kW}$ per chiller. Eight fans condense the refrigerant for each cooling unit located on the roof of the building. Chilling units are good maintained and conventionally highly automated. Operation profile of the chilling unit is between 09:00 and 22:00 $\mathrm{h}$ on the weekdays, 09:00 and 23:00 $\mathrm{h}$ on
Table 2

A list of BMS equipment

\begin{tabular}{lc}
\hline Device & Quantity \\
\hline PC for SCADA & 1 \\
Control panel (DDC-PLC unit; compact and & 8 \\
$\quad$ modular, 600 data points) & 22 \\
Temperature sensor (Ni $1000,-30$ to $\left.130^{\circ} \mathrm{C}\right)$ & 33 \\
Differential-pressure switch $(40-300 \mathrm{~Pa})$ & 22 \\
Three-way control valves (valves: $\mathrm{DN} 25-150$, & 11 \\
$\quad$ PN16; drives: $0-10 \mathrm{~V}$ continuous output) & \\
Frost-protection monitors $\left(-5\right.$ to $12^{\circ} \mathrm{C}$; switch & 22 \\
$\quad$ difference: $\left.2-6^{\circ} \mathrm{C}\right)$ & \\
Damper actuator $(0-10 \mathrm{~V}$ continuous output, & 11 \\
$\quad 15 \mathrm{Nm}$ with spring return $)$ & 11 \\
Humidity sensor $(0-10 \mathrm{~V}$ continuous input) & \\
Air quality sensor $(0-10 \mathrm{~V}$ continuous input) &
\end{tabular}

the weekends, 28 weeks per year. Estimated annual hours of operation are $2674 \mathrm{~h}$ starting from April through November. Cooling set point is $6-9^{\circ} \mathrm{C}$. Thirteen chilled water pumps are responsible for water flow through the circuits.

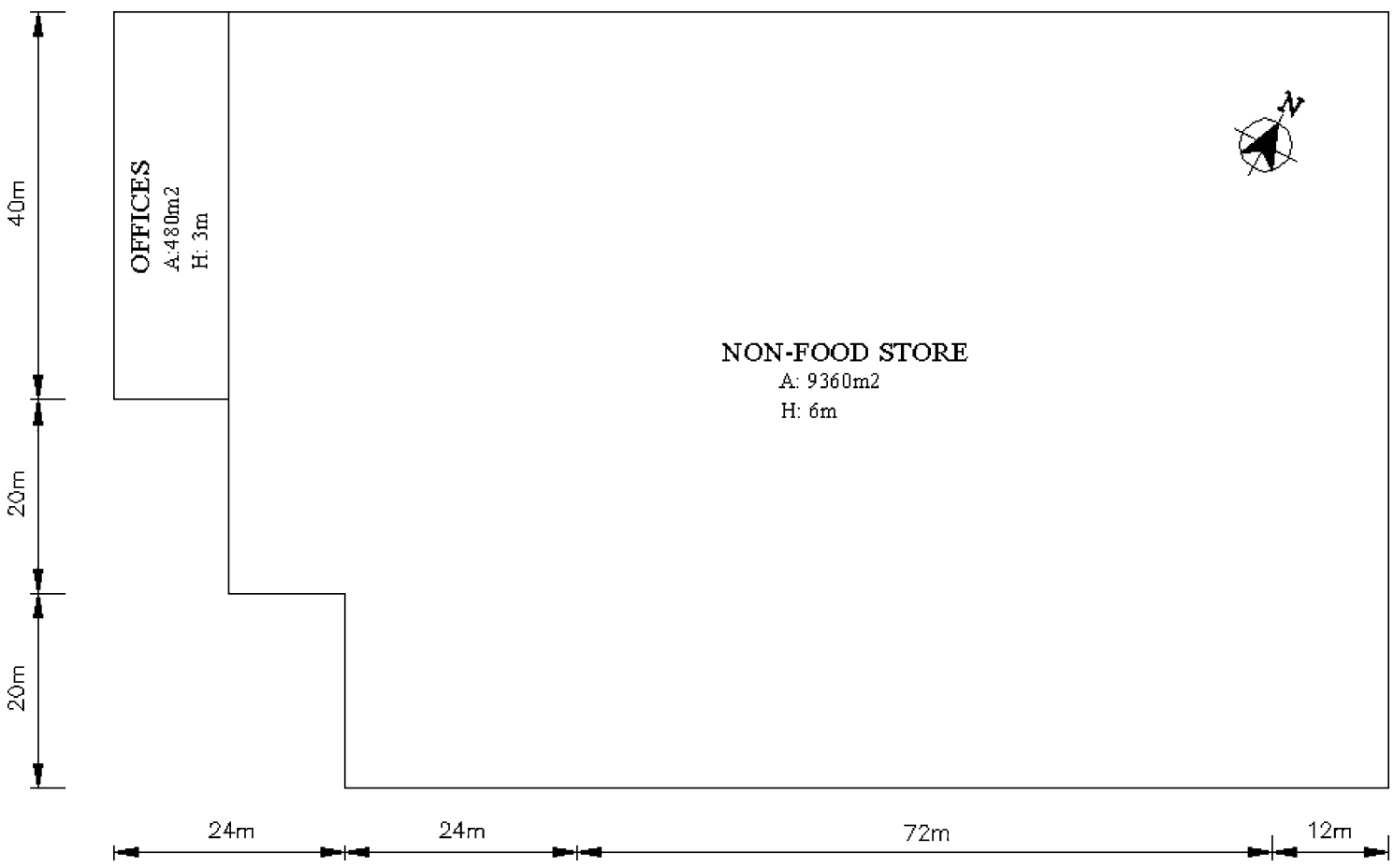

Fig. 2. A view of first floor plan. 


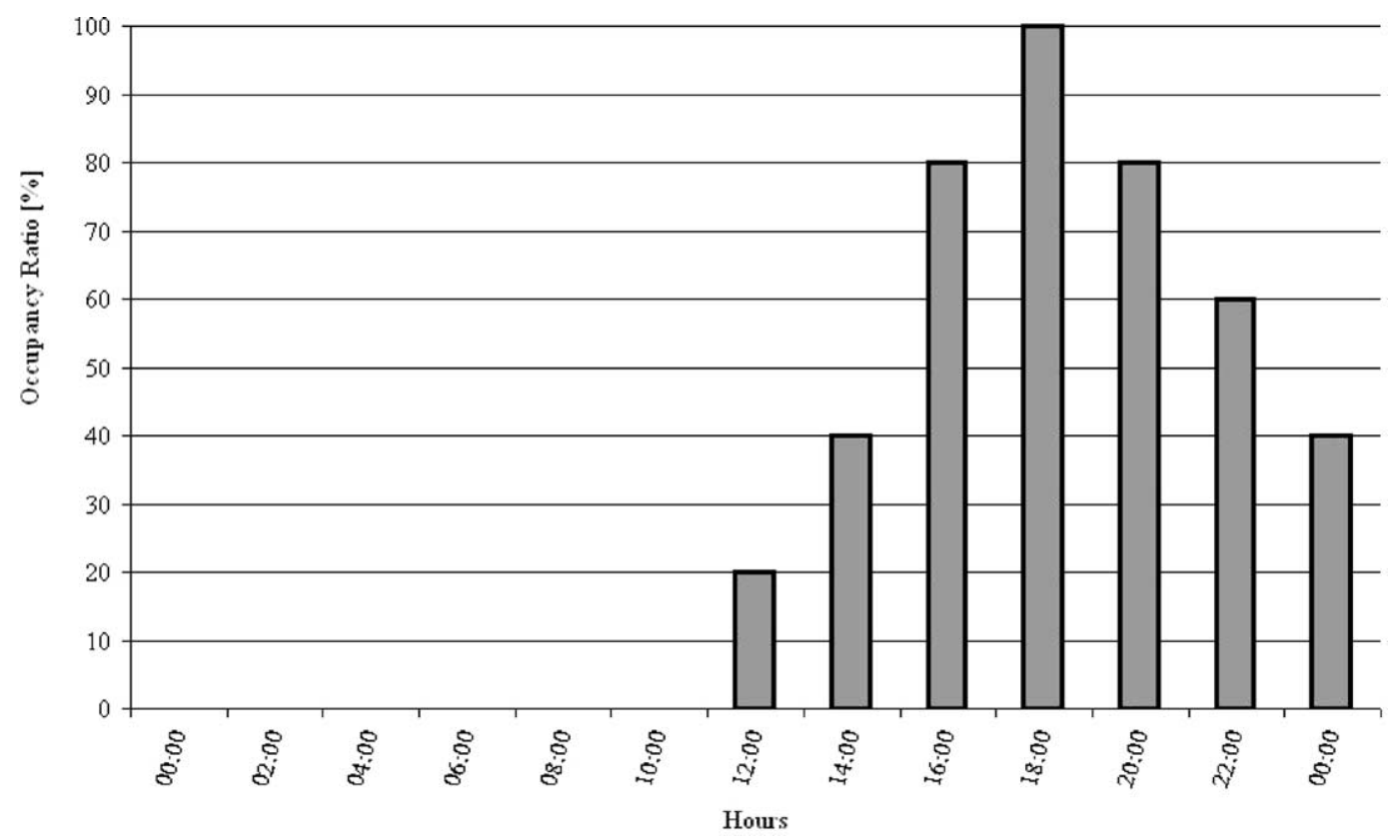

Fig. 3. Daily building occupancy profile.

Similar to the cooling coils, digital PPI cascade controllers are used to control the heating water flow through coils to maintain a set temperature inside the air-conditioned areas. Two LPG-fired hot water boilers supply the hot water to these coils. Boilers are maintained periodically and conventionally highly automated. Boilers are loaded and unloaded by a step controller conventionally to keep the water inside at a fixed set temperature $90-70^{\circ} \mathrm{C}$. The boiler has a total heating capacity of $870 \mathrm{~kW}$. Eight hot water pumps are responsible for the flow through the hot water circuit.

HVAC system is equipped with BMS that controls the temperature and time scheduled programs. With the help of Supervisory Control and Data Acquisition (SCADA), operator can handle the HVAC system efficiently and user friendly. Nine AHUs, 2 boilers, 16 pumps, 3 chillers and 14 exhaust fans can be controlled from the BMS, which is composed of the devices given in Table 2 .

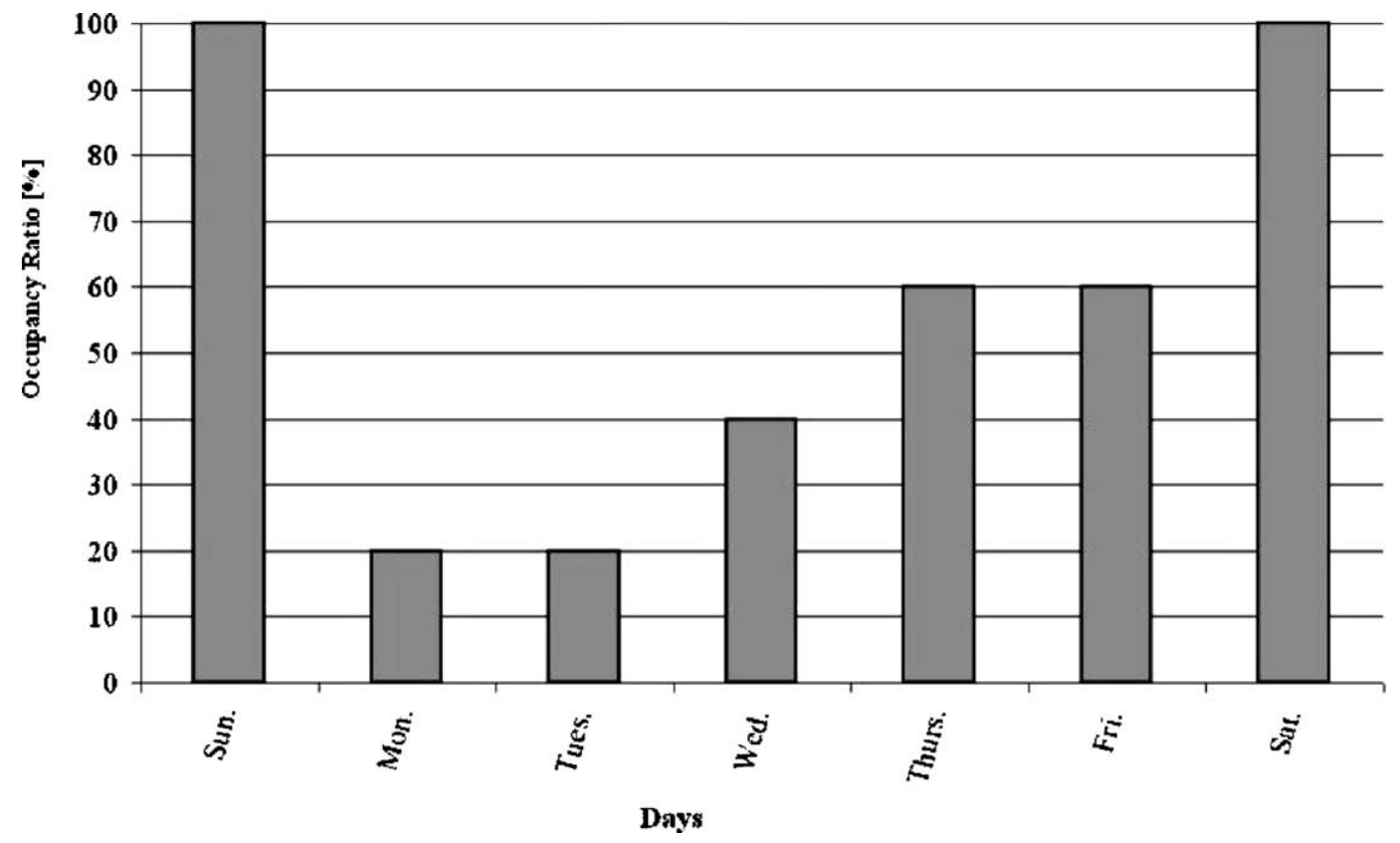

Fig. 4. Weekly building occupancy profile. 


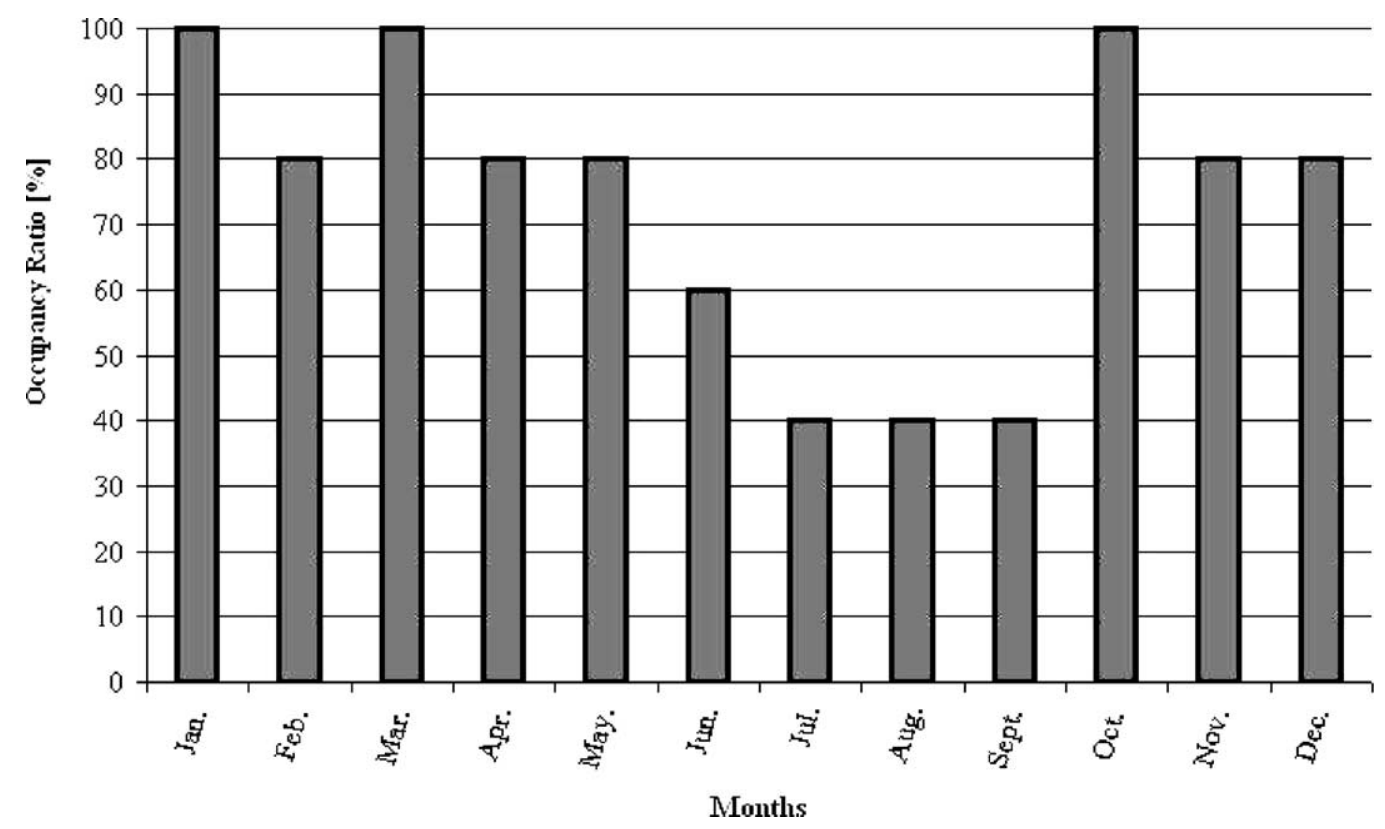

Fig. 5. Monthly building occupancy profile.

\section{Methodology}

A flow diagram of the methodology developed is presented in Fig. 7. The study started with a "walk through" audit to identify the energy usage of HVAC equipment, lights and other diverse equipment. A detailed energy audit was carried out to reach regular and reliable records of energy use to understand and control the energy management strategy. These records helped to identify changes in energy costs and consumption. The second step of the study was to identify an action plan to redefine the control parameters based on revisions of HVAC control strategies. Actual control strategies and parameters were analyzed and fluctuations from the set points were determined. The present study focused on hypermarket and non-food store AHUs because these areas are largest energy consumers and directly related to customer's comfort. New strategies such as optimum start-stop, free outside cooling (FOC) and night purge are implemented to AHUs as the third step.

\subsection{Energy audit}

To investigate energy saving potential, energy usage of the shopping centre was analyzed. Questionnaires were made

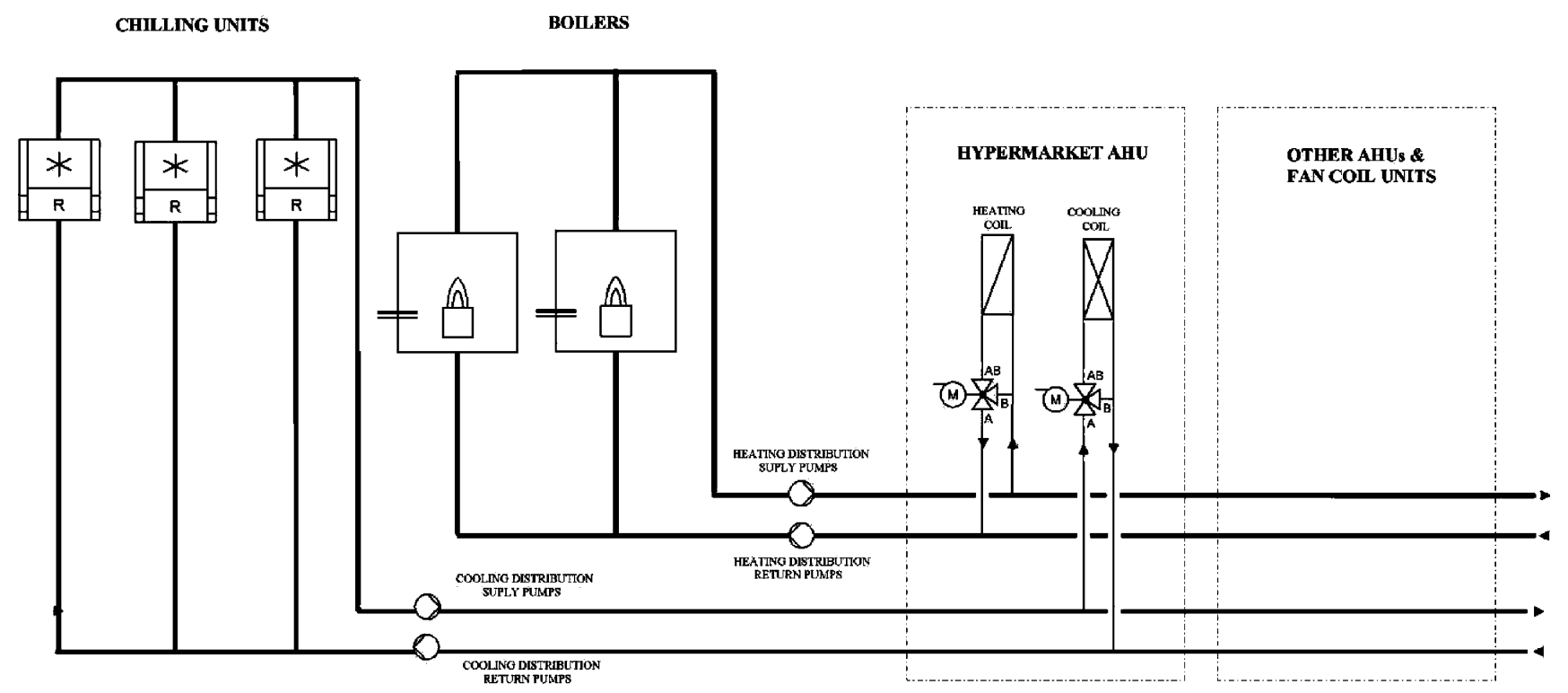

Fig. 6. Simplified heating and cooling distribution. 

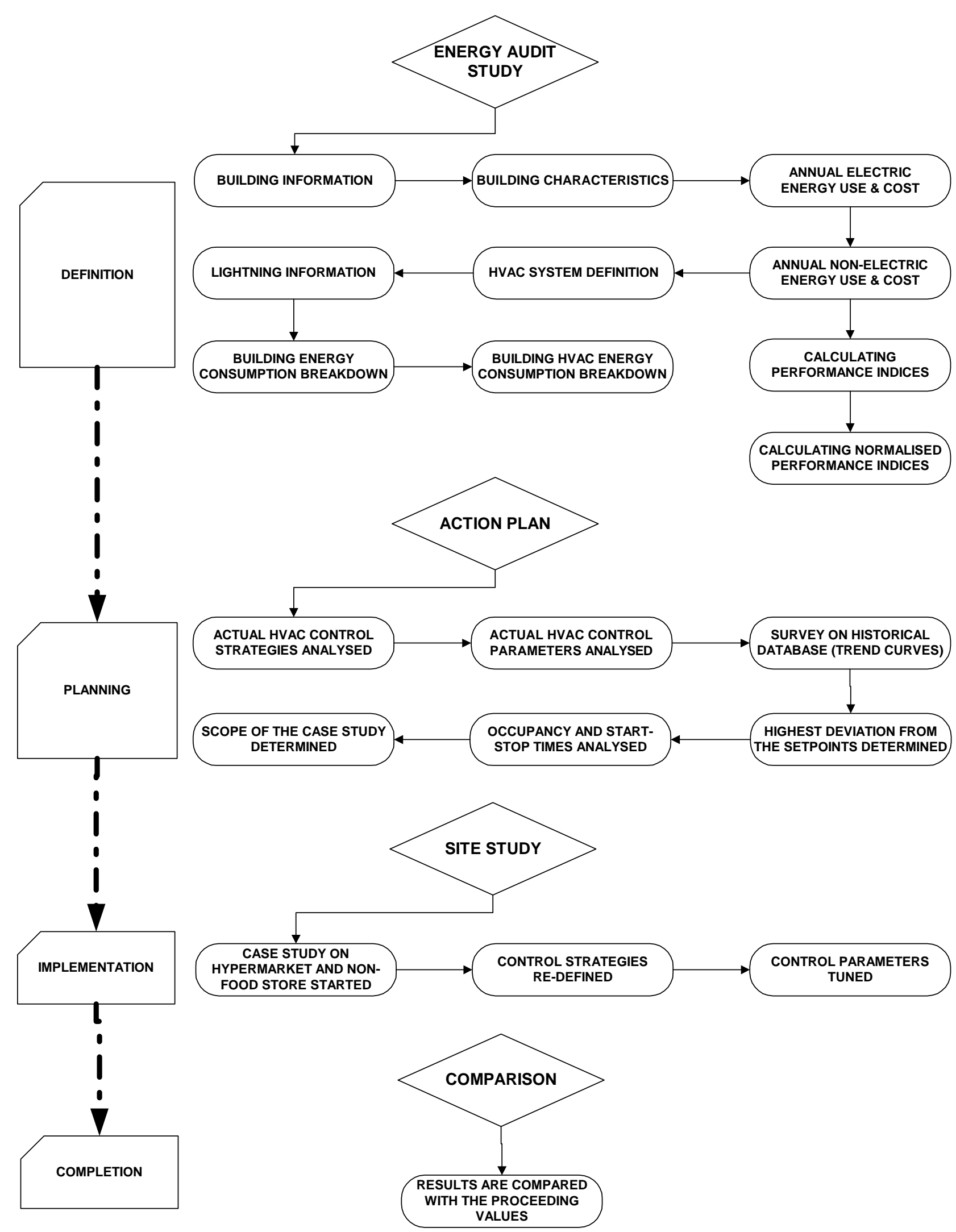

Fig. 7. A flow diagram of the methodology developed for the case study. 
and detailed investigation on energy invoices was also conducted.

To initialise the energy audit study, building information and building characteristics were analyzed. This study includes occupancy profiles and architectural locations of HVAC zones. HVAC system defined and energy consumption breakdown of the building was generated to compare electricity and fossil fuel consumption. Liquefied petroleum gas (LPG), of which utilisation as an energy source in Turkey is given in [8], is used as fossil fuel. To be able to understand the fluctuations of energy consumption, annual energy usage for electricity and LPG was plotted. Within this study, we focused on HVAC energy consumption and various components of the HVAC energy consumption were analyzed. To measure building energy performance, performance indices were calculated and compared with the yardsticks. Then, normalised performance indices were calculated.

The shopping centre has an ongoing non-systematic energy management program. These studies were very helpful to compose the database for this energy audit.

\subsubsection{Calculating the performance indices}

Performance indices give a measure of the energy use of a building, which can be compared with the yardsticks. They can indicate the potential for improvements and can be used to show progress over the time. They can also allow comparisons to be made between buildings in a group or estate [9].

Two separate indices are calculated for the shopping centre; one for electricity and the other for fossil fuels. The performance indices are obtained by dividing the annual building energy use by the floor area.

Annual energy usage for fossil fuels and electricity are compared with the yardsticks of UK Energy Efficiency Office [9] since in Turkey, such "energy consumption yardsticks" tables are not being defined to compare the facilities.

To refine the performance indices of the shopping centre, environmental and cost indices were added to be able to make a comparison. Effect of weather and exposure on the performance of a building, with a method to allow for these factors required. Adjustments of the performance indices for these factors produce a normalised performance index.

Overall performance indices provide a single measure of building performance, and can be expressed in terms of carbon dioxide $\left(\mathrm{CO}_{2}\right)$ emissions or energy costs. Overall, energy indices are useful for comparing a stock of buildings; however, separate fossil fuel and electricity performance indices are more useful to assist in deciding a course of action.

\subsection{Action plan}

Action plan given in Fig. 7 was originated and realised with the help of BMS. Advantages of the BMS are used without making any investment. In the existing system, con-
Table 3

Power consumption of AHUs

\begin{tabular}{llll}
\hline Zone & $\begin{array}{l}\text { Cooling coil } \\
\left(7-12^{\circ} \mathrm{C}\right)(\mathrm{kW})\end{array}$ & $\begin{array}{l}\text { Heating coil } \\
\left(90-70^{\circ} \mathrm{C}\right)(\mathrm{kW})\end{array}$ & $\begin{array}{l}\text { Fan power } \\
(\mathrm{kW})\end{array}$ \\
\hline Hypermarket AHU & 506.7 & 274.2 & 45 \\
Non-food store AHU & 400.1 & 295.4 & 45 \\
\hline
\end{tabular}

trol strategies are not clearly defined and control parameters are not site synchronised.

Aim of the action plan is to generate optimum start-stop times due to occupancy profile (not depending upon the operator), to implement control principles such as FOC and night purge and to tune PPI cascade controller for the sequence control for heating and cooling.

\subsection{Site study}

Site study is concentrated on hypermarket and non-food store AHUs.

\subsubsection{AHU system description}

Hypermarket and non-food store AHUs are typically the same. However, their heating-cooling capacities and fan powers are different (Table 3). Both of them use RA to mix with OA for energy conservation. Air enters to the AHU from OA damper and if needed mixed by RA. Air passes through a filter and then heating and cooling coils simultaneously. Supply air (SA) fan forces the air to ventilate through the conditioned space by diffusers. Air is aspirated from space by RA fan and if no mixing of air needed it exhaust by the exhaust air (EA) damper. Fig. 8 shows a flow diagram of the AHUs studied.

\subsubsection{Current control scenario}

Supply and return fans can directly be switched on from SCADA if they are in automatic position. These fans have interlocks in case of failure of operation. AHU operates as per the sequence 'heating coil-air dampers-cooling coil'. The parts of the sequence are formed in the controller. The measurement for the room-air temperature is taken in the RA duct. All control loops activate when supply and return fan status are on. OA and EA dampers close and RA damper opens when fans are off and modulate for temperature control when fan is on. Also, heating and cooling valves are closed when fans are off.

$\mathrm{P}+\mathrm{PI}$ cascade and a PI single controller are used. The SA and RA temperatures are measured by sensors of TM02 and TM03, respectively. The SA temperature is controlled by the PI auxiliary controller (control signals to CV01, CV02, AD01, AD02 and AD03). The set point for the PI control loop is formed by the P main controller, with the RA temperature as the controlled variable. The set point is lowered as the RA temperature rises, while it is raised as it falls. The control deviation is compensated by adjusting the control signals to CV01, CV02, AD01, AD02 and AD03. The min- 


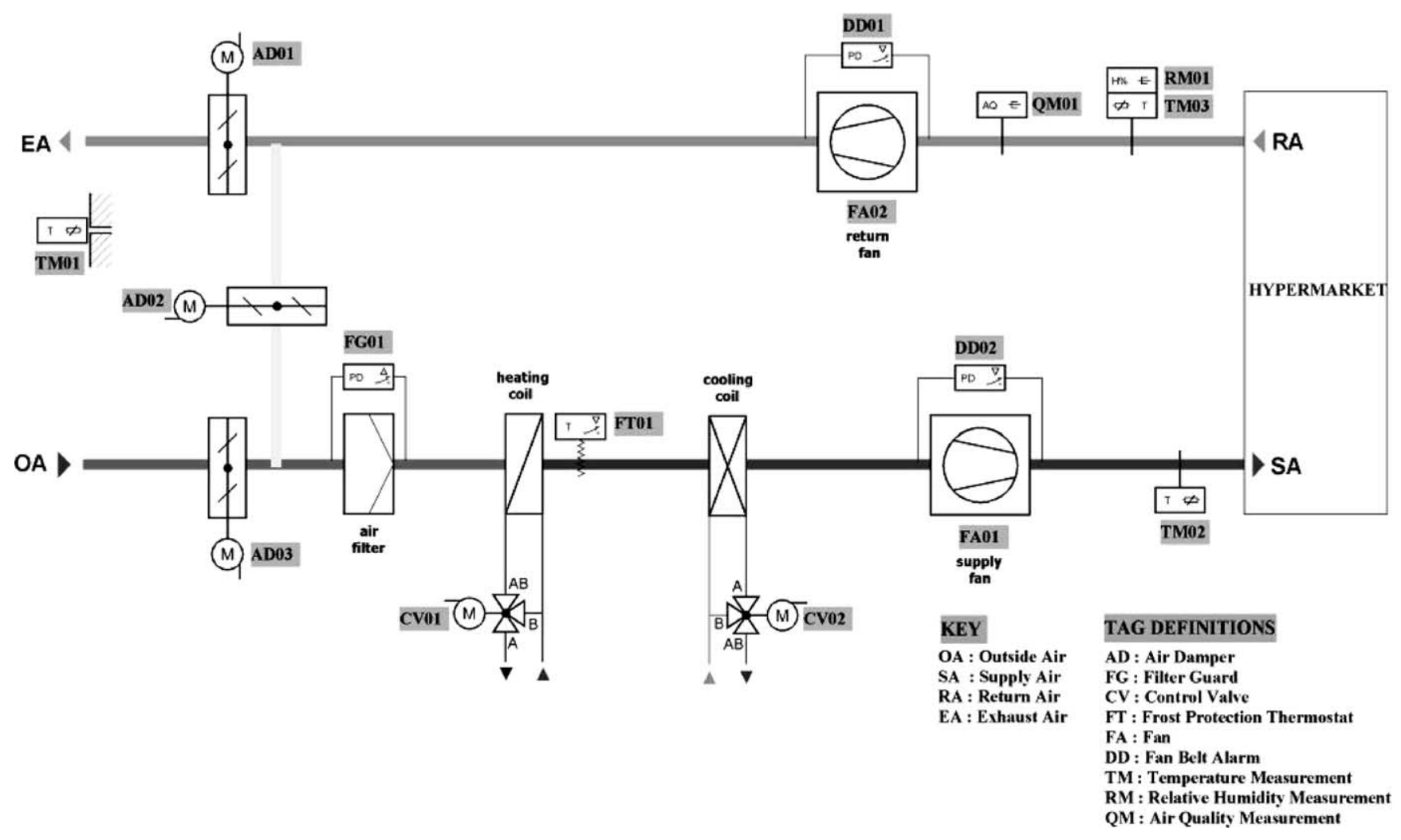

Fig. 8. A flow diagram of the AHU.

imum and maximum SA temperatures are given in the parameters of the blocks. Summer/winter changeover signal is decided in accordance with the difference between the outside temperature TM01 and the RA temperature. This signal converts the slopes of the air dampers.

The minimum position of the fresh-air damper is set by the user interface from SCADA view or from function block diagram (FBD). Return fan shall start anytime the supply fan starts. Differential-pressure switches monitor the ventilator's fan belt and the filter's clogging level. The frost-protection functions are triggered by a frost-protection monitor that opens the heating coil in case of activation and stops supply and return fans.

\subsubsection{Implemented control strategies}

To understand the implemented strategies and current control loops, a control block diagram of these two AHUs is plotted in Fig. 9. HVAC control strategies, such as optimum start-stop, FOC and night purge, are implemented to AHUs.

Optimum start-stop strategy calculates a lead-time to turn on or off heating or cooling equipment at the optimum time to bring temperatures to proper level at the time of occupancy. This strategy adjusts AHU stop time to allow stored energy to maintain the comfort level to the end of the occupancy period. During the optimum start period, AD01 and AD03 are fully closed because of non-occupancy.

Free outside cooling can be enabled by the operator from the SCADA. FOC controls the cooling of the space by utilising the low temperature at night. Significantly less cooling energy needs to be expended for hypermarket and non-food store that are pre-cooled in this way. Every evening at 18:00 h, the strategy saves OA temperature from TM01 and RA from TM03. The approximate maximum temperature is reached at about this time in the summer. If OA temperature is less then $25^{\circ} \mathrm{C}$ or if RA temperature is less than $22^{\circ} \mathrm{C}$, this block de-activates itself, which guarantees to work in the cooling season. One other interlock for the block is comparison of RA and OA temperatures. If the difference between RA temperature and OA temperature is less than $2{ }^{\circ} \mathrm{C}$, module de-activates. If RA temperature is less than $20^{\circ} \mathrm{C}$, module also de-activates. Whenever the module activates, it sends a signal to AD01 and AD03 to open 100\%.

Night purge strategy enables to use cool, night outdoor air to pre-cool the building before the mechanical cooling is turned on. To activate the strategy, cooling season shall be selected and RA temperature must be over $24^{\circ} \mathrm{C}$. Also, OA dew point shall be less than $16^{\circ} \mathrm{C}$.

\subsubsection{Tuning control parameters}

The efficiency of a control scheme to reduce energy use and to maintain comfort largely depends on proper controller tuning. The process was noisy that fluctuations from the set points are high. $\mathrm{P}$ controller calculates a set point for SA, while SA air temperature is controlled by the PI auxiliary controller (control signals to CV01, CV02, AD01, AD02 and AD03). Minimum and maximum limits for the SA are determined as 16 and $36^{\circ} \mathrm{C}$. The slope for the $\mathrm{P}$ main controller is 10 . The set point for the PI control loop is formed 


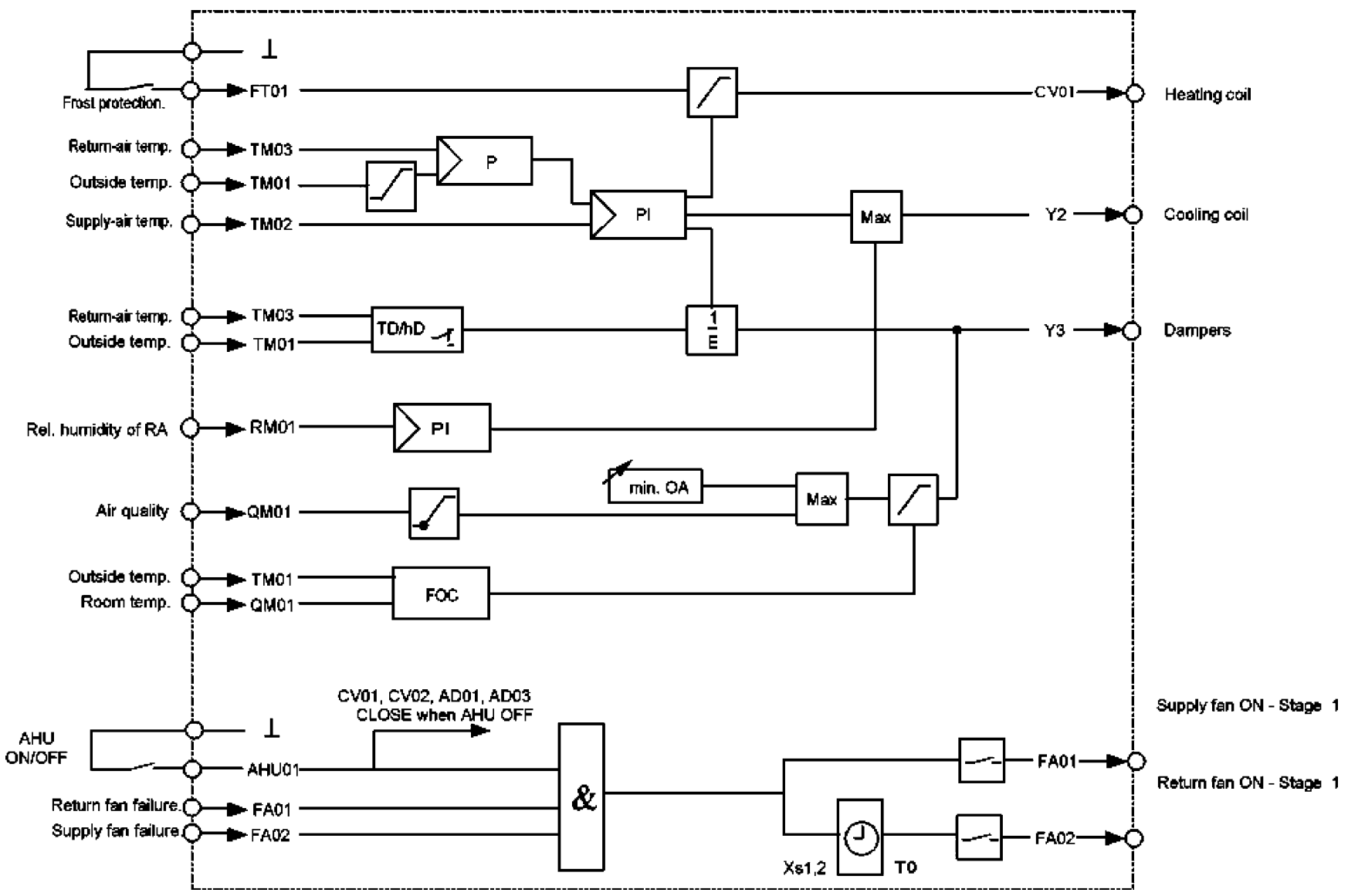

Fig. 9. Automatic control block diagram of the AHU.

by the $\mathrm{P}$ main controller, with the RA temperature as the controlled variable. The set point is lowered as the RA temperature rises, and is raised as it falls. The control deviation is compensated by adjusting the control signals to CV01, CV02, AD01, AD02 and AD03. Proportional band for the PI auxiliary controller is 12 and integral time is $180 \mathrm{~s}$. Reversal of the direction of operation of the control signal for AD01, AD02 and AD03 is determined by heating-cooling selector, which depends on OA and RA temperature. Output signal from the PPI controller is split into three in the sequence 'heating coil-air dampers-cooling coil', as shown in FBD.

Humidity control is made by a PI block, which is used only to maintain the humidity in the maximum limit. There are no humidifiers in the process, so only a drying by cooling coil is defined.

\section{Results and discussion}

\subsection{Energy audit}

Based on the questionnaires, energy utilisation of the shopping centre is $4,360,000 \mathrm{kWh}$ per year. Within the current energy management studies, approximate energy saving is $655,000 \mathrm{kWh}$ per year $(\sim 15 \%)$.
General energy consumption breakdown for the shopping centre is shown in Fig. 10. This gives an idea of general energy usage of the building. To understand the seasonal energy consumption fluctuations, annual electricity and fossil fuel (LPG) consumption are plotted in Fig. 11. This graph is very typical in which LPG and electricity demands are reverse. LPG demand increases in the heating season and peak demand is in January. On the other hand, electricity demand increases in the cooling season and peak demand is in July. Chilling units and industrial cooling have a consid-

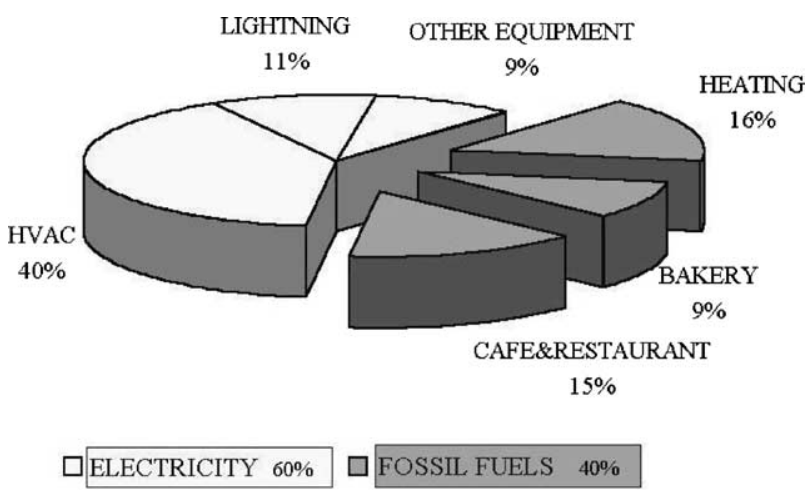

Fig. 10. General energy consumption breakdown including electricity and fossil fuels. 


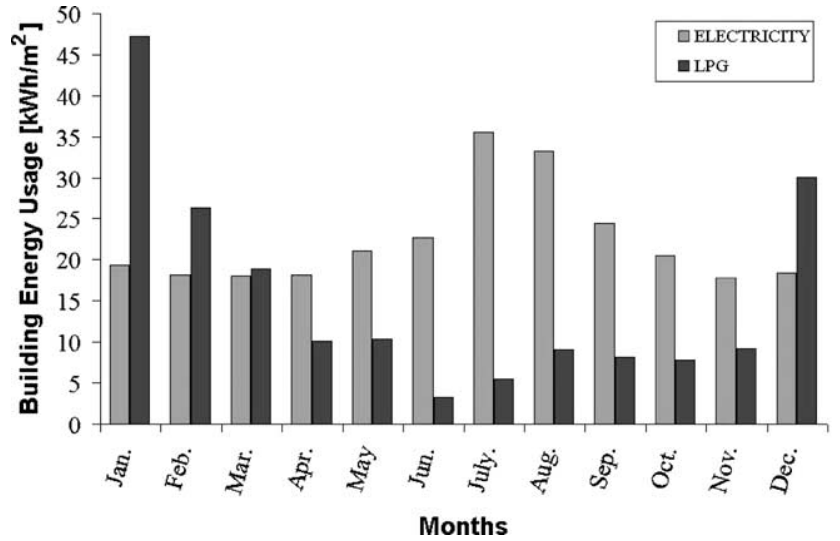

Fig. 11. A comparison of annual building energy usage.

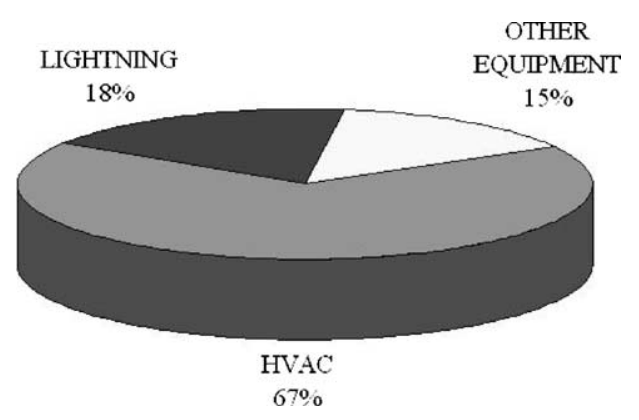

Fig. 12. Electrical energy consumption breakdown.

erable effect on electricity consumption, which increases in the summer season.

To be able to identify the largest electrical energy consumers, energy consumption is categorised into HVAC, lightning and other equipment and given in Fig. 12. The "other equipment" category includes the electrical devices in hypermarket, non-food store, restaurant, boiler room consumers, lifts, dishwashers, computers, etc. The HVAC equipment, which is the major energy consumer, constitutes approximately $67 \%$ of the total energy consumption. Thus, it has the largest energy saving potential. The reason for this is the large internal load in the form of people in the shopping centre, which can accommodate as many as 20,000 people per day on the weekends.

In Fig. 13, HVAC energy consumption was then broken down into the various components of the HVAC system. It is clear that cooling is the major energy consumer in the

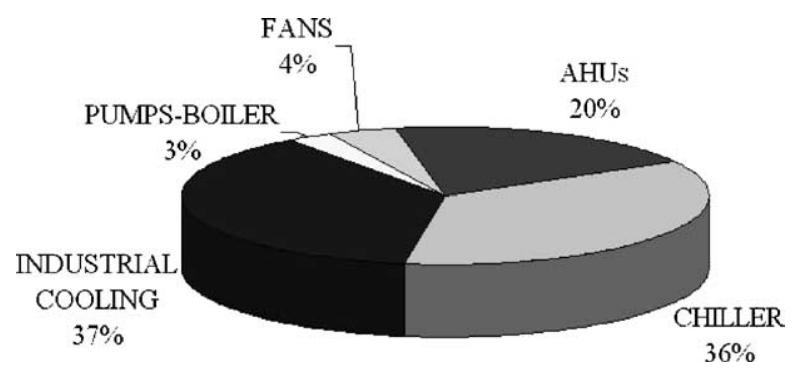

Fig. 13. HVAC energy consumption breakdown.
Table 4

Performance assessment for fossil fuels and electricity in the supermarkets [9]

\begin{tabular}{llll}
\hline & \multicolumn{2}{l}{ Yardstick $\left(\mathrm{kWh} / \mathrm{m}^{2}\right)$} \\
\cline { 2 - 4 } & $\begin{array}{l}\text { Low } \\
\text { consumption }\end{array}$ & $\begin{array}{l}\text { Medium } \\
\text { consumption }\end{array}$ & $\begin{array}{l}\text { High } \\
\text { consumption }\end{array}$ \\
\hline Fossil fuels & $<160$ & $160-290$ & $>290$ \\
Electricity & $<670$ & $670-920$ & $>920$
\end{tabular}

Table 5

$\mathrm{CO}_{2}$ performance index calculation

\begin{tabular}{lclc}
\hline & $\begin{array}{l}\text { Annual } \\
\text { energy use } \\
\left(\mathrm{kWh} / \mathrm{m}^{2}\right)\end{array}$ & $\begin{array}{l}\mathrm{CO}_{2} \\
\text { conversion } \\
\text { factor } \\
(\mathrm{kg} / \mathrm{kWh})\end{array}$ & $\begin{array}{l}\text { Annual } \\
\mathrm{CO}_{2} \\
\mathrm{emission} \\
\left(\mathrm{kg} / \mathrm{m}^{2}\right)\end{array}$ \\
\hline Gas & 184.9 & 0.20 & 36.98 \\
Oil & 0 & 0.29 & 0 \\
Coal & 0 & 0.32 & 0 \\
Electricity & 272.7 & 0.70 & 190.89 \\
Total energy cost $/ \mathrm{m}^{2}$ & & & 227.87 \\
\hline
\end{tabular}

shopping centre with a total share of $73 \%$ within the HVAC equipment. Of this, $36 \%$ is for chilling units, which feed the AHUs and FCUs to cool the space, $37 \%$ is for industrial cooling, which cools the foods to maintain fresh for long periods. AHUs are the second largest energy consumers with $20 \%$.

\subsubsection{Calculating the performance indices}

In this study, the shopping centre is categorised in "supermarkets", thus comparison is made according to Table 4. In the shopping centre, annual electricity and LPG uses amount to 272.7 and $184.9 \mathrm{kWh} / \mathrm{m}^{2}$, respectively. These figures indicate that the building has very low electricity consumption and medium fossil fuel consumption.

To calculate overall performance indices, annual energy usage indices are used. $\mathrm{CO}_{2}$ and cost conversion factors for the fuels are given in Tables 5 and 6, respectively.

Cost conversion factors are typical values for the year 2002 as billed to shopping centre. Overall assessment for $\mathrm{CO}_{2}$ emissions and energy costs is made by using values given in Tables 7 and 8 .

Table 6

Cost performance index calculation

\begin{tabular}{lclc}
\hline & $\begin{array}{l}\text { Annual } \\
\text { energy use }\end{array}$ & $\begin{array}{l}\text { Cost } \\
\text { conversion } \\
\text { factors } \\
(\mathrm{US} \$ / \mathrm{kWh})^{\mathrm{a}}\end{array}$ & $\begin{array}{l}\text { Annual } \\
\text { cost }\end{array}$ \\
\hline Gas $\left.\$ / \mathrm{m}^{2}\right)$
\end{tabular}

\footnotetext{
${ }^{a}$ Annual mean values for the year 2002 in Turkey.
} 
Table 7

$\mathrm{CO}_{2}$ performance assessment for buildings with fossil fuels and electricity supply [9]

\begin{tabular}{llll}
\hline & \multicolumn{2}{l}{ Yardstick $\left(\mathrm{kg} \mathrm{CO}_{2} / \mathrm{m}^{2}\right)$} \\
\cline { 2 - 4 } & Low emission & Medium emission & High emission \\
\hline Supermarkets & $<500$ & $500-700$ & $>700$ \\
\hline
\end{tabular}

Table 8

Cost performance assessment for buildings with fossil fuels and electricity supply [9]

\begin{tabular}{llll}
\hline & \multicolumn{2}{l}{ Yardstick $\left(\mathrm{US} \$ \mathrm{~m}^{2}\right)$} \\
\cline { 2 - 4 } & Low cost & Medium cost & High cost \\
\hline Supermarkets & $<78$ & $78-108$ & $>108$ \\
\hline
\end{tabular}

Performance indices are normalised for weather and exposure, as given in Table 9. Normalised performance index shows the actual performance of the building.

\subsection{Action plan}

The scope of the action plan is to redefine the control parameters based on revisions of HVAC control strategies. Actual control strategies were analyzed and compared with values generated from the energy audit study. Cooling is the major energy consumer in HVAC system but no major changes were made in cooling control strategy. Chillers are well controlled conventionally and there is no need to define extra strategy for energy saving for cooling. So, we focused on AHUs as the second major energy consumers in HVAC group. To start an experimental study, the major consumers from the AHUs are determined. Related to the survey on the historical database and trend curves of the SCADA (novaPro), the fluctuations from the set points are observed and retrofit study is focused on the hypermarket and non-food store AHUs. These AHUs are the major energy consumers comparing with the other AHUs and set point deviations are very high. Furthermore, they are directly related to client's comfort.

\subsection{Tuning control parameters}

HVAC control strategies, such as optimum start-stop, FOC and night purge, are implemented in the hypermarket and non-food store AHUs. The results of energy consumption and savings are listed in Table 10.

Table 10 indicates that some strategies may have disadvantages, while some have high energy saving potential. For example, night purge strategy consumes extra fan power to

Table 9

Calculation of normalised performance indices

\begin{tabular}{|c|c|c|c|c|c|}
\hline & Gas & Fossil fuel oil & Other & $\begin{array}{l}\text { Total of } \\
\text { fossil fuels }\end{array}$ & $\begin{array}{l}\text { Total of } \\
\text { electricity }\end{array}$ \\
\hline Total energy consumption $(\mathrm{kWh})(A)$ & $2,958,216$ & 0 & 0 & $2,958,216$ & $4,363,104$ \\
\hline Space heating energy $(\mathrm{kWh})(B)$ & $1,183,286$ & 0 & 0 & $1,183,286$ & $2,923,279$ \\
\hline Non-space heating energy $(\mathrm{kWh})(C=A-B)$ & $1,774,929$ & 0 & 0 & $1,774,929$ & $1,439,825$ \\
\hline Find the degree days for the energy data year $(D)$ & & & & \multicolumn{2}{|c|}{1223} \\
\hline Weather correction factor $(E=2462 / D)$ & & & & \multicolumn{2}{|c|}{2.013} \\
\hline Obtain exposure factor for heating energy use $(F)$ & & & & \multicolumn{2}{|c|}{0.9} \\
\hline $\begin{array}{l}\text { Annual heating energy use for standard conditions (kWh) } \\
\qquad(G=B \times E \times F)\end{array}$ & & & & $2,143,759$ & $5,296,104$ \\
\hline Normalised energy use (kWh) $(H=C+G)$ & & & & $3,918,688$ & $6,735,929$ \\
\hline Find floor area $\left(\mathrm{m}^{2}\right)(J)$ & & & & 16,000 & 16,000 \\
\hline $\begin{array}{l}\text { Find the normalised performance indices } \\
\qquad\left(\mathrm{kWh} / \mathrm{m}^{2}\right)(K=H / J)\end{array}$ & & & & 245 & 421 \\
\hline
\end{tabular}

Table 10

A summary of energy and environmental data with estimated saving in the summer case

\begin{tabular}{|c|c|c|c|c|}
\hline Daily consumption & $\begin{array}{l}\text { Without any } \\
\text { strategy }\end{array}$ & $\begin{array}{l}\text { Optimum } \\
\text { start-stop }\end{array}$ & FOC & $\begin{array}{l}\text { Night } \\
\text { purge }\end{array}$ \\
\hline Return fan (kWh) & 630 & 462 & 630 & 756 \\
\hline Supply fan (kWh) & 630 & 462 & 630 & 756 \\
\hline Total fan (kWh) & 1260 & 924 & 1260 & 1512 \\
\hline Saving (\%) & - & 26.6 & - & -20 \\
\hline Cooling coil (MJ) & 25,537 & 18,715 & 22,454 & 23,713 \\
\hline Saving (\%) & - & 26.7 & 12 & 7.1 \\
\hline Overall electricity usage (kWh) & 2125 & 1558 & 2020 & 2302 \\
\hline Saving (\%) & - & 26.6 & 4.9 & -8.32 \\
\hline Average $\mathrm{CO}_{2}$ emission $(\mathrm{kg})$ & 1487 & 1090 & 1414 & 1611 \\
\hline
\end{tabular}


cool down the building in the midnight, but the delay for starting the chilling units brings advantage on energy usage. FOC has no effect on the fan power consumption, but should have a great potential in the spring or autumn. This strategy activates only in the occupancy periods. Optimum start-stop strategy is very important because it saves energy independent to the seasonal changes.

There are two important results obtained from the study carried out in the shopping centre: One is the performance of the building is very good for electricity consumption and within the accepted limits for fossil fuel (LPG) consumption. The other one is energy saving with the retrofit studies, which were performed in the hypermarket and non-food store AHUs are estimated as $22 \%$ in the summer case.

\section{Conclusions and recommendations}

This paper documents a case study aimed to understand the energy performance of a shopping centre and develop HVAC control scenarios to minimize energy usage. To initialise a case study in the shopping centre studied, a methodology is developed. This methodology has four phases, namely: (a) definition of building characteristics and HVAC system by conducting an energy audit; (b) planning an action plan; (c) implementation of the site study; and (d) completion by comparing the results with the proceeding values.

To start a retrofit study in the shopping centre, an energy audit study is performed and the potential for energy savings is investigated. The characteristics of the building and its HVAC system are defined. Within the frame work of the energy audit study, the performance of the building is investigated. As a result, the building electricity and fossil fuel (LPG) consumption are defined as medium level and low level, respectively.

An action plan is defined, while the present study focuses on the hypermarket and non-food store AHUs. Control scenarios of these AHUs are deeply investigated and the revisions are made. The HVAC control strategies, such as optimum start-stop, FOC and night purge, are implemented. The control loops and parameters are tuned due to the characteristics of the building. Energy saving obtained by these retrofit studies is approximately $22 \%$ in the summer case.
The effect of changing the control strategy is usually difficult to predict, so every strategy shall be tested for every season. Also, the success of implementing efficient energy management and HVAC control is coupled with understanding the performance of mechanical and control systems.

Current results should not be a realistic measure of implemented HVAC control strategies because they represent only the summer period. To be able to define the best control strategy, the studies should be carried out for every season and a long term. For other AHUs and HVAC devices, such control strategies should be implemented. It also should be noted that this case study was conducted without making any investment to the building.

BMSs should be a much more effective tool for energy management. It needs more engineering and teamwork to use the capacity of the system more efficiently. A certified energy manager should be employed to investigate the potential for energy savings and should observe the energy audit continuously.

\section{References}

[1] M.W. Ellis, E.H. Mathews, Needs and trends in building and HVAC system design tools, Building and Environment 37 (2002) 461-470.

[2] The Ministry of Energy and Natural Resources of Turkey (MENR), 2003, available from http://www.enerji.gov.tr.

[3] Z. Utlu, A. Hepbasli, A study on the evaluation of energy utilization efficiency in the Turkish residential-commercial sector using energy and exergy analysis, Energy and Buildings 35 (11) (2003) 11451153.

[4] M.B. Aereboe, Energy management strategies for facility managers, SA Refrigeration and Air Conditioning 11 (1995) 43-51.

[5] M.W. Ellis, Practical evaluation and integrated simulation of building HVAC system performance, Masters thesis in Mechanical Engineering, University of Pretoria, 1996, pp. 2.57-2.64.

[6] E.H. Mathews, D.C. Arndt, M.F. Geyser, Reducing the energy consumption of a conference centre-a case study using software, Building and Environment 37 (2002) 437-444.

[7] Washington State University Energy Program, Energy Audit Workbook, 2003, available from http://www.energy.wsu.edu/ftpep/pubs/rem/energyaudit.

[8] A. Hepbasli, A.A. Karakus, M. Erkek, Liquefied petroleum gas (LPG) as an energy source in Turkey, Energy Sources 25 (5) (2003) 373382.

[9] Energy Efficiency Office (EEO), Department of the Environment, Introduction to Energy Efficiency in Shops and Stores, Best Practice Programme, UK, 1994. 